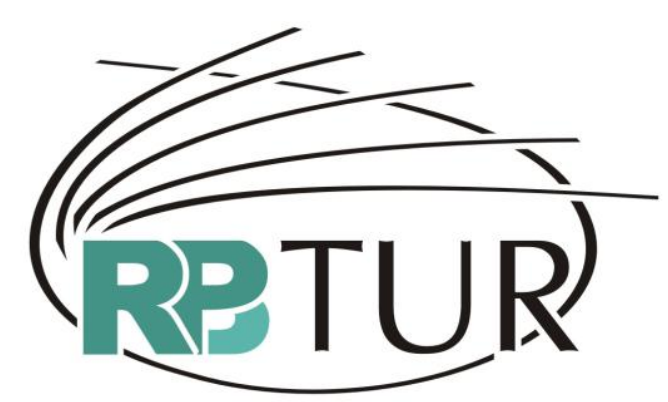

REVISTA BRASILEIRA DE PESQUISA EM TURISMO

\title{
RELATO DA IX REUNIÃO DE ANTROPOLOGIA DO MERCOSUL (CURITIBA/PR)
}

\section{REPORT ON THE $9^{\text {TH }}$ ANTHROPOLOGY MEETING OF MERCOSUR (CURITIBA/PR, BRAZIL)}

\section{RELATO DE LA XI REUNIÓN DE ANTROPOLOGÍA DEL MERCOSUR (CURITIBA/PR, BRASIL)}

Margarita Barretto ${ }^{1}$

Durante a IX Reunião de Antropologia do Mercosul (10 a 13 de julho de 2011), que teve como tema Culturas, Encontros e Desigualdades, o turismo foi discutido em dois momentos: na Mesa Redonda 17, intitulada Encontros e Desencontros entre Visitantes e Visitados: Novos Paradigmas, da qual participaram os professores Alvaro Banducci Jr. (UFMS) como coordenador; Rodrigo de A. Grünewald (UFCG) e Alejandro Otamendi, (UBA); e no Grupo de Trabalho (GT) 65, intitulado Turismo Cultural e Patrimônio - Encontros e Desencontros de uma Relação Dialógica, coordenado por Margarita Barretto (FURB/UFSC).

Em um evento marcado por muitas ausências dos colegas dos países vizinhos em função de cancelamento de vôos por causa das cinzas expelidas pelo complexo vulcânico Puyehue-Cordón Caulle (Chile), e de outras em função de restrições orçamentárias e/ou administrativas das universidades, os trabalhos do GT se reduziram a dois dias, dos três inicialmente previstos, e

1 Docente da Fundação Universidade Regional de Blumenau - FURB. Editora da Revista Brasileira de Pesquisa em Turismo (RBTur). Email: barretto.margarita@gmail.com 
com apresentações menos controladas pela tirania do relógio e comentários mais reflexivos por parte dos participantes.

A mesa redonda foi coordenada por Alvaro Banducci Jr. que abriu a mesma contando a história dos grupos de turismo nas Reuniões de Antropologia do Mercosul, que começaram em 1999 com apenas seis participantes inscritos e culminaram na RAM de 2009 em Buenos Aires, quando o GT de turismo foi o segundo em número de inscrições (quase oitenta trabalhos submetidos) e o primeiro em assiduidade durante o próprio evento.

O Prof. Álvaro fez também um histórico das mudanças ocorridas na forma de abordar o turismo a partir da antropologia, que durante a década de 1980 estiveram marcadas pelos construtos aculturação e impactos, colocando sempre o turismo e os turistas como "invasores sem exército" (Jurdao Arrones, 1992) ou "hordas" (Turner; Ash, 1991) provenientes dos países ricos, que passavam como um rolo compressor pelos lugares visitados, deixando um rastro de destruição do meio ambiente natural e cultural. Lembrou Banducci Jr. que este "impacto" dos visitantes sobre os visitados é um pouco menos drástico e que as populações visitadas reagem e encontram suas formas de negociar com os turistas. Tocando num tema muito polêmico e delicado, para demonstrar o alcance dos novos olhares sobre a relação entre visitantes e visitados, menciona que até o turismo sexual, tido por alguns teóricos como a quintessência da exploração dos visitados pelos visitantes, tem formas reflexivas e dialógicas. Há uma negociação permanente, como mostram os estudos realizados por Silva e Blanchette (2005), Bem (2005), Piscitelli (2007), só para citar os mais representativos no Brasil onde se revela que moças que trabalham no mercado do sexo há também exercem seu poder de sedução junto aos turistas procurando (e não raro conseguindo) negociar um casamento e a emigração, para as próprias e até para seus pequenos filhos.

Alejandro Otamendi discorreu sobre o estado da arte das pesquisas sobre turismo a partir da antropologia na Argentina, que são mais recentes e tem ainda poucos expoentes. Tanto o turismo quanto a pesquisa em turismo tiveram na Argentina um percurso ligeiramente diferente ao do Brasil e não 
houve tanta influência do paradigma dos impactos, desde que as pesquisas, por ter começado um pouco mais tarde, - um dos primeiros livros é Carvajal (1992) - já começaram a analisar os processos com uma ótica mais ampla. Lembrou também Otamendi o pioneirismo do portal www.naya.org.ar (Notícias de Antropologia e Arqueologia) onde em 2001 foi realizado o primeiro congresso virtual de turismo e o espaço conquistado no Congresso Argentino de Antropologia Social onde no fim do corrente ano, por segunda vez, haverá um GT discutindo turismo, o primeiro tendo sido em Posadas, Misiones, em 2008. Coincidentemente foi nessa mesma cidade em que, em 1999, aconteceu o primeiro GT de turismo na RAM. ${ }^{2}$

Rodrigo de A. Grünewald fez um relato das suas próprias mudanças conceituais durante os dezesseis anos de contato com seus sujeitos de pesquisa, o grupo indígena Pataxô habitante do sul do estado da Bahia, experiência esta documentada em livros e artigos científicos nacionais e internacionais. Como sempre, seu trabalho provocou inúmeras perguntas e comentários que levaram a riquíssimas reflexões e a ultrapassar em quase uma hora o tempo previsto para a finalização da atividade. Em todos estes, o Prof. Rodrigo pode sentir a insuficiência de construtos como impactos, aculturação, autenticidade para explicar o que observava diretamente em campo. O próprio conceito de comunidade perde aplicabilidade a partir do momento que os grupos que moram em Santa Cruz Cabrália têm percepções e convicções diferentes daqueles que moram em Porto Seguro. Entre os próprios grupos há divergências e conflitos inter geracionais. Construtos como a autenticidade encenada, que marcaram a reflexão na antropologia aplicada ao turismo podem ser aplicados, mas não no sentido de crítica que McCannel (1999) utilizava. Assim como a cultura "ocidental" representa sua cultura, eles representam a sua. Assim como a cultura "ocidental" vê normal que uma pessoa vista roupa importada, eles entendem que podem usar enfeites

2 Impossível discorrer sobre pesquisa em turismo na Argentina sem mencionar a revista Estudios y Perspectivas en Turismo, atualmente no vigésimo aniversário, dirigida pela pesquisadora Dra. Regina Schlüter, da Universidade Nacional de Quilmes. No entanto, não se trata de uma revista de antropologia propriamente dita, embora podem ser encontrados artigos de antropólogos ou de temas de antropologia. 
oriundos de outras etnias; assim como a arte "ocidental" se modifica, eles entendem que seu artesanato pode ser modificado para atender novos mercados. E assim como os outros habitantes do Brasil eles procuram oferecer um bom produto a seu mercado consumidor, no caso da Jaqueira, por exemplo, os turistas culturais.

Nas três apresentações sobressaiu-se a categoria negociação para descrever os processos que acontecem, tanto entre garotas de programa e turistas, entre os Pataxô e os turistas e entre as diferentes gerações Pataxô, ou no turismo esotérico das serras de Córdoba (Argentina) onde Otamendi tem realizado grande parte das suas pesquisas, onde a negociação é sobre a imagem do Uritorco a ser vendida.

Negociação que nada mais é do que uma forma de sintetizar dialogismo e reflexividade e hibridismo cultural, que são os novos paradigmas para pensar a relação turismo, cultura e sociedade no século XXI.

As apresentações do $\mathrm{GT}^{3}$ começaram com um pôster de Anna B. Z. Koslinski (UFPE) sobre a turistificação dos Maracatus-nação pernambucanos. A pesquisadora desvenda a complexa relação destes conjuntos tradicionais com o poder público, e sua reação perante a imposição do formato espetáculo dentro do carnaval do estado, do qual são a maior atração turística e como a religião progressivamente vai tomando espaço para diferenciar os maracatus nação de outras formas híbridas que cederam à indústria cultural. Ana M. C. Beber (PUCRS/UFRGS) apresentou o trabalho "Trutas, paçoca e pinhão: turismo cultural e comida em contexto de hibridismo cultural". No mesmo, a pesquisadora revela que no turismo rural são oferecidas aos turistas formas híbridas de alimentação, que incluem ingredientes da comida cotidiana dos turistas em suas cidades de origem e ingredientes da culinária local. Revela também que há comidas que os locais consomem com exclusividade, reforçando que a alimentação é um patrimônio que querem manter como próprio. Sandro Campos Neves (UFRRJ) discorreu sobre "A economia indígena

3 Os resumos podem ser consultados no site do congresso: http://www.ram2011.org/ procurando em Programação e Grupos de Trabalho. 
do turismo: notas sobre a apropriação do turismo pelos Pataxó de Coroa Vermelha", desvendando que, a identidade coletiva deste grupo étnico é construída e expressa-se utilizando as atividades econômicas dentro de uma lógica própria, que não é a da competitividade capitalista. Esse processo constitui uma ressemantização indígena da atividade turística e de outras a ela relacionadas, como o artesanato, onde ninguém quer se sobressair de forma individual. Também dentro do tema turismo indígena, Adiles Savoldi (UFFS) apresentou "Terra indígena Reserva Aldeia Condá: a cultura Kaingang em cena", relatando como este grupo étnico se apresenta perante outras culturas em eventos relacionados ao dia do índio, tentando ao mesmo tempo, numa relação dialógica, responder ao índio imaginário que as pessoas querem ver e mostrando qual é o índio real. Para este diálogo procuram assessoria para apresentar os alimentos, para dialogar com as religiões e com a mentalidade capitalista. Emilene L. Sousa (UFMA) apresentou um curioso trabalho denominado "O medo como estratégia: resistência ao turismo na Ilha do medo", local de Maranhão onde a população reagiu à tentativa do poder público de implantar o turismo, com estratégias de amedrontar os turistas com lendas criadas para tal finalidade. O trabalho mostra a complexa teia de conflitos, entre residentes e visitantes e nativos e instâncias governamentais. Sandra de Sa Carneiro (UERJ), co-autora, com Nieves Herrero (USC) do trabalho "Guardianes del Camino: el discurso de las Asociaciones de Amigos en la peregrinación jacobea", desvenda as complexas relações, ora de cooperação, ora de conflito, entre o Estado, a sociedade civil, o mercado e a Igreja no (antes sagrado) Caminho de Santiago, na Espanha. Vera M. Guimarães (UFJF), em "Elementos do turismo cultural nas experiências de intercâmbio de jovens universitários" apresenta um estudo em que as viagens de intercâmbio contêm uma forma híbrida de turismo cultural mas ao mesmo tempo de possibilidades de trabalho e de ganhos curriculares para o futuro. Larissa M. Pacheco (FACISA/CELER) apresentou a pesquisa "Patrimônio e Turismo: expressões identitárias no Centro Histórico de uma cidade litorânea no sul do Brasil, Garopaba,SC", onde mostra os conflitos e tensões em torno 
da restauração de uma praça e de uma igreja, as artimanhas do poder público para impor o seu projeto sob o rótulo de "diálogo" e a resposta da população, assim como as tensões dentro de moradores de diferentes áreas espaciais. Mariela F. da Silveira apresentou seu projeto de pesquisa em andamento "Patrimônio cultural e turismo na Freguesia de Nossa Senhora da Lapa do Ribeirão da Ilha", no decorrer do qual encontrou relações conflitivas entre os líderes comunitários e os moradores no que concerne à turistificação do patrimônio do bairro que é um dos mais antigos povoamentos da Ilha de Santa Catarina. Camila Moraes (UniRio) apresentou "A alegoria das Casas-telas: turismo e patrimônio no Museu de Favela, um esforço para valorizar o patrimônio de uma favela carioca e torná-lo atrativo para os turistas, dentro de um projeto do Governo para procurar alternativas econômicas para a mesma. A arqueóloga Patrícia Salatino (UBA/Conicet) discorreu sobre "Turismo y patrimonio arqueológico en la Quebrada de Humahuaca, Jujuy, Argentina", local declarado patrimônio da humanidade sem que houvesse um consentimento dos moradores locais. Mostra as tensões entre saber acadêmico, estado e guias de turismo, que não se reportam muito ao passado, mas sim a falar sobre os problemas do presente. Desvenda neste cenário o papel da arqueologia na construção da identidade local e no fortalecimento das comunidades para o diálogo com o "outro global" trazido pelo turismo internacional.

Finalmente, Hernanda Tonini (IFRG) "Uva e vinho como elementos norteadores da identidade cultural na Serra Gaucha", a partir de uma pesquisa realizada com Joice Lavandoski sob orientação de Margarita Barretto. Nesta pesquisa os entrevistados revelam que a uva e o vinho continuam sendo suas marcas de identidade, que resistem às transformações ocorridas em outras manifestações culturais, mesmo com modificações na forma de plantio (o parreiral deixou lugar à espaldeira), na elaboração (a pipa deixou lugar ao inox). O enoturismo permite esta continuidade com a tradição, deixando os produtores satisfeitos tanto pelas possibilidades econômicas que oferece, quanto de socialização. 
Um elemento comum que apareceu em todas as apresentações foi a intervenção do poder público em algum momento do processo, promovendo e não raro forçando a adesão a projetos de turismo e/ou à transformação de manifestações culturais em turísticas. Isto desmistifica visões anteriores do turismo como algo gerado de forma exógena. As "hordas" de Turner chegavam do nada, os invasores sem exército também. Nos exemplos aqui apresentados promove-se o turismo, estimula-se a vinda dos visitantes, chega-se ao ponto de tentar a chantagem com a população como no caso da Ilha do Medo, onde o estado somente liberaria infra-estrutura básica urbana se os nativos aceitassem a implantação do turismo.

No caso dos Maracatu, o poder público intervém impondo mudanças, e os maracatu-nação respondem reflexivamente introduzindo a religião como forma de diferenciar-se, como forma de preservar seu patrimônio.

Um processo semelhante acontece em São José dos Ausentes, onde os proprietários rurais foram, de certa forma, intimados a participar dos projetos de turismo rural e, na atualidade conseguem preservar como patrimônio privado certas comidas que não oferecem aos turistas, coisa que também acontece entre os índios da aldeia Condá, e os Pataxô.

Religião e comida passam a ser formas de resistência, de autoafirmação; uma resposta reflexiva, um limite de negociação. Poderiam ser consideradas âmbitos sagrados que as populações visitadas se reservam para si, oferecendo produtos específicos para os turistas que estariam no âmbito do profano? São possibilidades que se abrem para a análise antropológica.

Em todos os casos estão presentes conflitos e tensões que não se limitam à dicotomia entre visitantes e visitados como foi enfatizado pelos primeiros pesquisadores da década de 1980. Na Ilha do Medo a tensões são entre os nativos e os turistas, os nativos e os planejadores de turismo enviados pelo estado, e entre estes e os antropólogos que foram chamados como mediadores para "sensibilizar" a população. Em Garopaba, entre os nativos e os de fora e entre os nativos com os moradores "dos becos". Em 
Ribeirão da Ilha entre nativos e lideranças locais, em Jujuy entre arqueólogos, turistas, população local, estado e guias de turismo.

Ao mesmo tempo, se apresentam formas híbridas de produtos turísticoculturais, como as comidas para turistas, com a presença até de um "fogão turístico" no caso de São José dos Ausentes, ou a indianidade para turistas, que inclui a apresentação do índio ecológico e romântico que os visitantes procuram no caso dos Kaingang, que, como índios reais chegam a incomodar, e cujas crianças, como toda criança cosmopolita que vive no mundo atual, querem comida de supermercado. Finalmente, a dessacralização do Caminho de Santiago, onde a peregrinação transformou-se num bem material a procura do diploma outorgado a quem faz o percurso, que antes devia ser feito a pé e com mínimo conforto e hoje pode ser realizado de outras formas, com direito a foto com um peregrino "autêntico", numa transformação da esfera do sagrado para a esfera do profano com a anuência da Igreja que precisa dos números das estatísticas de visitação (270 mil peregrinos no último ano!) para mostrar a revitalização do catolicismo, e com a ajuda do estado que precisa dos peregrinos, chamados pelo neologismo turisgrinos, para dar uma alternativa econômica a aquela região pobre da Galícia.

Pode-se ver nestas apresentações, que os paradigmas dos anos 1980 e 1990 não são mais suficientes para explicar a complexidade de relações sociais, econômicas, políticas e culturais das quais o turismo é parte integrante, e que conceitos como reflexividade, dialogismo, cosmopolitismo e hibridismo cultural podem ser os paradigmas do século XXI para os estudos de turismo a partir da antropologia.

\section{Referências}

BEM, A. S.. A dialética do turismo sexual. Campinas: Papirus, 2005 CARVAJAL, J.. La cara oculta del viajero. Buenos Aires: Biblos 1992 JURDAN ARRONES, F.. Los mitos del turismo. Madrid: Endymion, 1992 MacCANNEL, D. The tourist. A new theory of the leisure class. Berkeley: University of California Press, 1999 
ISSN: $1982-6125$

PISCITELLI, A. Sexo tropical em um pais europeu. Migração de brasileiras para Itália no marco do "turismo sexual" internacional. Estudos Feministas, Florianópolis, 15(3), pp. 171-744 Dezembro 2007. Disponível em http://www.scielo.br/pdf/ref/v15n3/a14v15n3.pdf

SILVA, A.P; BLANCHETTE, T.. "Nossa Senhora da Help", sexo, turismo e deslocamento transnacional em Copacabana. Cadernos Pagu (25), julhodezembro de 2005, pp.249-280. Disponível em http://www.scielo.br/pdf/\%0D/cpa/n25/26529.pdf

TURNER, L.; ASH, J.. La horda dorada. El turismo internacional y la periferia del placer. Madrid: Endymion, 1991

\section{Site Citado}

http://www.naya.org.ar/turismo/congreso/index.htm

Artigo recebido em julho de 2011.

Aprovado para publicação em agosto de 2011. 